(2) Open Access Full Text Article

\title{
Intravitreal ketorolac for the treatment of chronic cystoid macular edema after cataract surgery
}

\author{
This article was published in the following Dove Press journal: \\ Therapeutics and Clinical Risk Management \\ 12 February 2016 \\ Number of times this article has been viewed
}

\section{Miltiadis K Tsilimbaris \\ Chrysanthi Tsika \\ George D Kymionis}

Department of Ophthalmology, University of Crete, Heraklion, Greece
Correspondence: Miltiadis K Tsilimbaris Department of Ophthalmology, University of Crete Medical School, PO Box 2208, 71003 Heraklion, Greece Tel +3028 I 039235 I

$\mathrm{Fax}+3028 \mathrm{I} 0542094$

Email tsilimb@med.uoc.gr
Purpose: To report two cases of chronic postoperative cystoid macular edema, resistant to topical therapy, treated with consecutive intravitreal injections of ketorolac tromethamine.

Methods: Four daily intravitreal injections of $500 \mu \mathrm{g} / 0.05 \mathrm{~mL}$ of ketorolac were given to each patient. Complete clinical examination and OCT were performed before every injection, 1, 2, 3 weeks, and 1,3, and 6 months after the last injection. Fluorescein angiography was performed at baseline examination, 1, 3, and 6 months after the last injection.

Results: In both cases, the edema regressed and visual acuity increased. At 6 months after the last injection, the leakage was significantly reduced at the fluorescein angiography.

Discussion: Both cases responded favorably to the consecutive intravitreal administration of ketorolac tromethamine. The long-lasting remission of the macular edema in these chronic cases underlines the therapeutic potential of these agents when delivered intravitreally.

Keywords: postoperative CME, intravitreal, ketorolac, NSAIDs

\section{Introduction}

Postoperative cystoid macular edema (CME) represents a rare, self-limiting complication after intraocular surgery ( $<1 \%$ in uneventful operations), but sometimes it may become chronic ( $>6$ months) and reduce the visual acuity (VA), especially in complicated cases. ${ }^{1}$

The treatment of postoperative CME remains problematic as well-designed large clinical trials with long-term follow-up are lacking. ${ }^{2}$ Topical nonsteroid anti-inflammatory drugs (NSAIDs) have doubtful effect, ${ }^{3}$ while topical and intravitreal steroids have well-recognized side effects.

Due to their possible better safety profile, NSAIDs have recently attracted interest as alternative anti-inflammatory agents for intravitreal use. In clinical practice, intravitreal NSAIDs have been tested in most entities that result in macular edema such as Irvine-Gass syndrome, ${ }^{4-6}$ uveitic $\mathrm{CME},{ }^{7,8}$ and diabetic macular edema (DME)., ${ }^{4,6,9,10}$

Ketorolac tromethamine is one of the NSAIDs that have been tested intravitreally and the agent that we have used in the present work. It is a nonselective COX-inhibitor and a small molecule (molecular weight: $255 \mathrm{Da}$ ) with a short clearance from the vitreous cavity (half-life $\sim 3$ hours after intravitreal administration in rabbits). It has a safe intravitreal toxicity profile $\mathrm{e}^{1-13}$ and in the past we were able to demonstrate a favorable effect after a single injection of ketorolac in patients with chronic postoperative CME; however, edema regression was observed usually some days after the injection. $^{14}$

Hereby, we present two cases of chronic CME after complicated cataract surgery both patients were treated with consecutive daily intravitreal injections of ketorolac 
tromethamine (TORADOL ${ }^{\circledR} 30 \mathrm{mg} / \mathrm{mL}$, Recordati, Italy). Both cases responded favorably in this modified administration protocol.

\section{Case I}

An 81-year-old female, presented with decreased vision due to postoperative CME in the right eye. She had a history of complicated cataract surgery (posterior capsular rupture, anterior vitrectomy, and anterior segment intraocular lens insertion) 3 years before presentation. CME was diagnosed 7 months after the operation and showed no response to topical treatment (NSAID [ketorolac tromethamine $0.4 \%$ coll, qid] and corticosteroid drops [dexamethasone $0.3 \%$ coll, qid] for 6 months). No other ocular disease that predispose to the appearance of CME coexisted preoperatively. The patient was lost in follow-up with the persisting chronic CME, without any further ophthalmological consultation, to our knowledge. At presentation (3 years after the operation), the corrected distance visual acuity (CDVA) was 20/125 and the CME was detectable at biomicroscopy, optical coherence tomography (OCT; Stratus OCTC, Carl Zeiss Meditec, Dublin, CA, USA), and fundus fluorescein angiography (FFA; Retinal camera TRC-50DXC), Topcon Corp., Tokyo, Japan) (Figure 1A). After institutional approval was obtained from the University of Crete as well as written informed consent was signed, the patient received four consecutive intravitreal injections of ketorolac tromethamine (500 $\mu \mathrm{g} / 0.05 \mathrm{~mL}$ per injection, one injection per day).

Complete ophthalmologic examination and OCT scans were performed at baseline $(\mathrm{B} / \mathrm{L})$, before every injection and
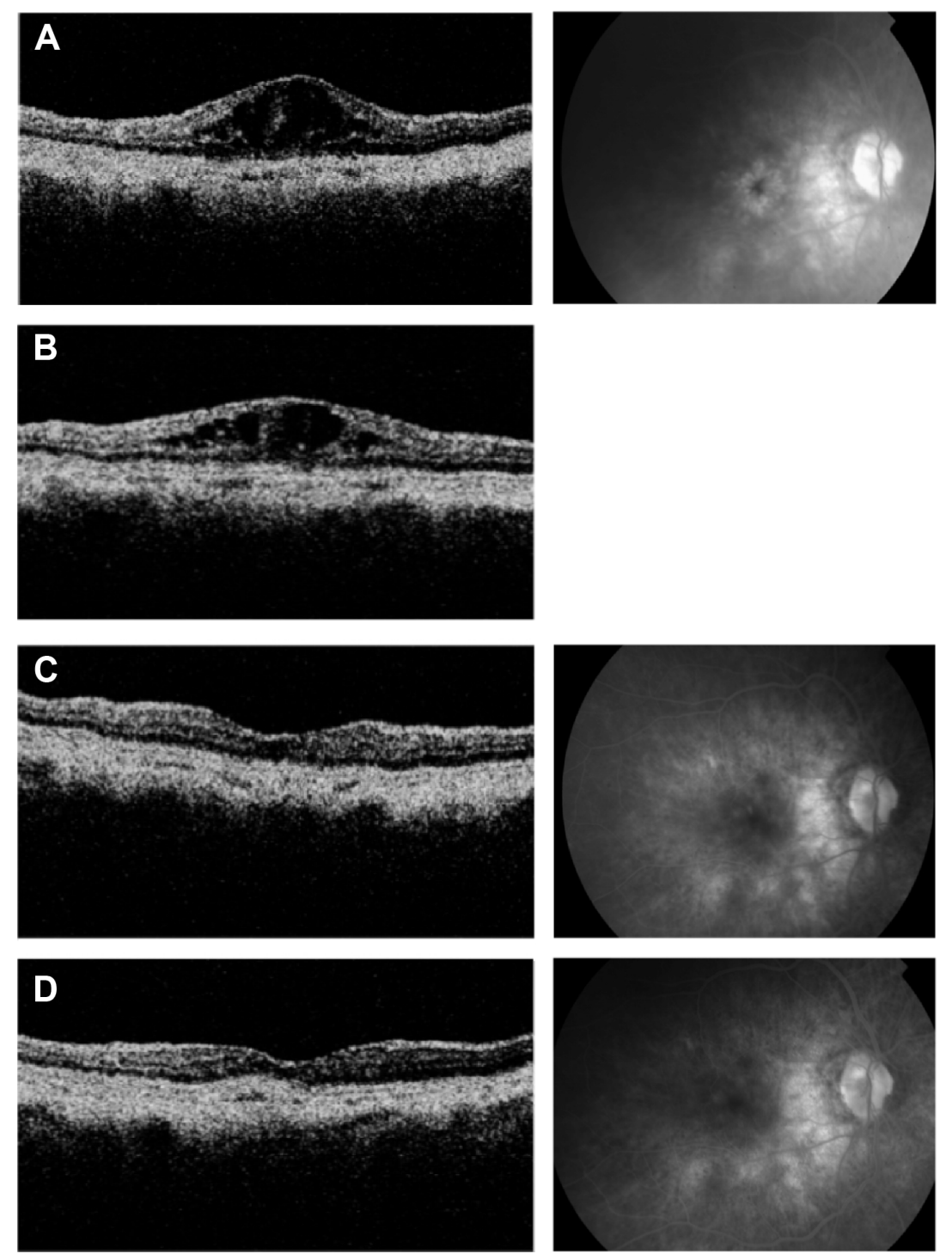

Figure I Case I. (A) OCT and late phase FFA at B/L, before the first intravitreal injection of ketorolac tromethamine. (B) OCT I4 days post the fourth injection. (C) OCT and late phase FFA 30 days post the fourth injection. (D) OCT and late-phase FFA 6 months post the fourth injection.

Abbreviations: B/L, Baseline; FFA, fundus fluorescein angiography; OCT, optical coherence tomography. 
at every follow-up visit at 1, 2, 3, 4 weeks, 3, and 6 months after the last injection. Macular thickness was calculated, by the OCT scans, as the average retinal thickness of the nine Early Treatment Diabetic Retinopathy Study foveal map subfields and is reported as mean macular thickness (MMT). An FFA was performed at $\mathrm{B} / \mathrm{L}, 1,3$, and 6 months after the last injection.

At B/L, the CDVA was $20 / 125$, the intraocular pressure (IOP) was $14 \mathrm{mmHg}$, and the MMT at OCT was $550 \mu \mathrm{m}$. At 2 weeks, the CDVA was 20/65, the IOP was $13 \mathrm{mmHg}$, and the MMT was $278 \mu \mathrm{m}$ (Figure 1B). At 1 month, the CDVA was 20/50, the IOP was $14 \mathrm{mmHg}$, and the MMT was $200 \mu \mathrm{m}$, and the CME was significantly reduced in the FFA (Figure 1C). At 6 months, the CDVA was 20/30, the IOP was $13 \mathrm{mmHg}$, the MMT was $170 \mu \mathrm{m}$, while the CME remained significantly reduced in the FFA (Figure 1D).

\section{Case 2}

A 65-year-old female presented with decreased vision and chronic postoperative CME. She had a history of complicated cataract surgery in her right eye (posterior capsular rupture, posterior champer intraocular lens in the sulcus) 17 months before presentation. At the time, she had received a 4-month course with topical anti-inflammatory treatment, commencing with the CME diagnosis ( 2 weeks after the operation), but without success. The treatment included corticosteroid drops (dexamethasone $0.3 \%$ coll, 1 drop every 2 hours with weekly tapering), and an NSAID agent (ketorolac tromethamine coll $0.4 \%$, qid). Meanwhile, the patient remained under observation, without any further anti-inflammatory treatment, until the time of presentation.

At presentation, the CDVA in the right eye was 20/65 and apart from the CME, minor retinal pigment epithelium changes at the macular area (mild age-related macular degeneration [AMD] according to the AREDS I study) were observed. No ocular disease that predispose for the appearance of CME coexisted preoperatively. The CME was detected in the OCT (Stratus OCTC, Carl Zeiss Meditec, Dublin, CA, USA) and the MMT was calculated as described in the previous case and was found to be $545 \mu \mathrm{m}$ (Figure 2A). FFA confirmed the diagnosis (Retinal camera TRC-50DX@, Topcon Corp.).

After institutional approval was obtained and informed consent was signed, the patient received four consecutive intravitreal injections of ketorolac tromethamine, $500 \mu \mathrm{g} / 0.05$ $\mathrm{mL}$ per injection, one injection per day.

Complete ophthalmologic examination and OCT scans were performed at $\mathrm{B} / \mathrm{L}$ visit and at 1, 2, 3, 4 weeks, 3, and 6 months visits, after the last injection. An FFA was performed at $\mathrm{B} / \mathrm{L}, 1,3$, and 6 months after the last injection.
At B/L, the CDVA was 20/65, the IOP was $12 \mathrm{mmHg}$, and the MMT in OCT was $540 \mu \mathrm{m}$ (Figure 2A). At 2 weeks, the CDVA was 20/40, the IOP was $13 \mathrm{mmHg}$, and the MMT was $351 \mu \mathrm{m}$ (Figure 2B). At the first month's visit, the CDVA was 20/30, the IOP was $11 \mathrm{mmHg}$, the MMT in OCT was reduced to $347 \mu \mathrm{m}$, and the leakage in FFA was relatively reduced (Figure 2C). At 3 months, the CDVA was 20/30, the IOP was $12 \mathrm{mmHg}$, the MMT in OCT was $300 \mu \mathrm{m}$, and the leakage in FFA was significantly reduced (Figure 2D). At 6 months, the CDVA was further improved to $20 / 20^{-2}$, the IOP was $12 \mathrm{mmHg}$, the MMT in OCT was normalized to $250 \mu \mathrm{m}$, and the leakage in FFA was significantly reduced (Figure 2E).

\section{Discussion}

Both patients presented here had long-lasting chronic CME after complicated cataract surgery that responded to the administration of intravitreal ketorolac tromethamine. In both cases, the edema subsided for at least 6 months after treatment. No complications such as IOP increase, retinal detachment, or endophthalmitis were observed.

Till today, there is no gold standard treatment for postoperative CME. Topical NSAIDs, corticosteroids, or their combinations are applied in uneventful and complicated cases. ${ }^{15}$ Intravitreal corticosteroids are preferred for complicated CME cases, but their side effects (IOP increase) limit their use.

During the last years, the intravitreal use of NSAIDs for the treatment of macular edema has received significant attention. Ketorolac tromethamine was the first NSAID delivered intravitreally in patients with macular edema of various etiologies with no topical or systemic complications. ${ }^{6}$ Since then, several NSAIDs (ketorolac, diclofenac) have been tested intravitreally for such entities as uveitic $\mathrm{CME},{ }^{7,8}$ $\mathrm{DME}^{4,6,9,10}$ as well as choroidal neovascularization. ${ }^{16}$ Interestingly, in some cases their therapeutic results are comparable with triamcinolone (eg, in DME). ${ }^{17,18}$ The use of intravitreal NSAIDs in postoperative CME, however, is reported scarcely. ${ }^{4,5}$

Our cases were chronic CME cases that exhibited regression as well as a significant increase in the visual acuity, shortly after four consecutive injections of $500 \mu \mathrm{g} / 0.05 \mathrm{~mL}$ of ketorolac tromethamine (1-2 weeks). At the end of the 6 months follow-up, both patients had improved VA (20/30 and $20 / 20^{-2}$ ).

Intravitreal ketorolac has a safe retinal toxicity profile ${ }^{13}$ even in high dosage. ${ }^{11,12}$ Histological evaluation after intravitreal administration of the commercially available ketorolac did not reveal any toxic effect at the retinal level. ${ }^{11,12}$ Moreover, clinical use of a dose higher than the one used in 

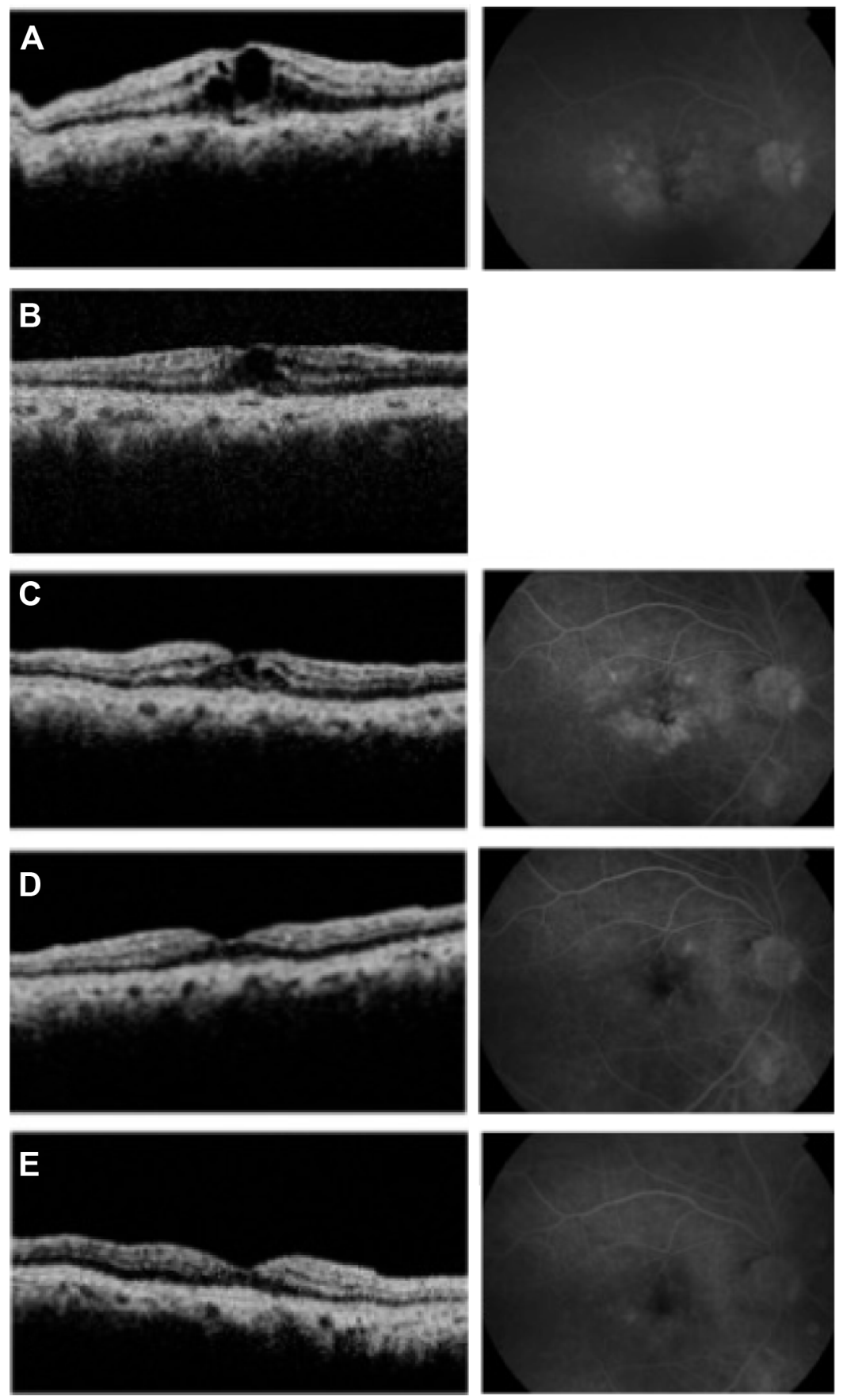

Figure 2 Case 2. (A) OCT and late-phase FFA at B/L, before the first intravitreal injection of ketorolac tromethamine. (B) OCT I4 days post the fourth injection. (C) OCT and late-phase FFA 30 days post the fourth injection. (D) OCT 90 days post fourth injection and late-phase FFA 90 days post the fourth injection. (E) OCT and late-phase FFA 6 months post the fourth injection.

Abbreviations: B/L, Baseline; FFA, fundus fluorescein angiography; OCT, optical coherence tomography.

our patients ( $3 \mathrm{mg}$ compared to $2 \mathrm{mg}$ ) was found to be safe without any sign of toxicity.

In the present work, we have chosen to administrate ketorolac due to the well-established kinetic and toxicity data that already exist in the literature, as mentioned earlier. Moreover, in the past we were able to demonstrate some effect after a single injection of ketorolac in patients with chronic postoperative CME. ${ }^{14}$ These results were in line with the hypothesis that the pathophysiologic mechanism of postoperative CME lies mainly on the prostaglandins' pathway of arachidonic acid metabolism and as such is expected to respond to COX-inhibitors. Ketorolac is a small molecule (molecular weight: $255 \mathrm{Da}$ ) and its clearance from the vitreous cavity is very short (half-life $\sim 3$ hours after intravitreal administration in rabbits). We speculated that this could be the reason for the short duration of the effect 
that we had observed after the administration of a single injection in the past. ${ }^{12}$ In the patients presented here, we adopted a therapeutic scheme of four consecutive daily injections in an effort to extend the presence of the drug in the vitreous cavity and thus maximize its therapeutic effect. The dosage was four injections of $500 \mu \mathrm{g} /$ day. Both patients showed decrease of the edema after 1-2 weeks and regression after 1 month follow-up, without recurrence at 6 months. A possible explanation for the latent effect of the molecule might be related with the kinetics of the substance within the ocular tissues. While published studies related to clearance of ketorolac from the vitreous cavity are available, its bioavailability in the retina and the rest ocular tissues is substantially unknown. The delay of the metabolism of the anti-inflammatory agent and its metabolites within the retina and retinal pigment epithelium could give a potential explanation to our findings and demands further research.

Based on the findings of this work, we think that prolongation of the presence of ketorolac in the vitreous cavity can lead to considerable augmentation of its therapeutic action. In its current pharmacotechnical form, multiple daily injections are necessary to extend its presence in the target tissues. The development of an extended release formulation of ketorolac or some other NSAID may present a very appealing solution for this limitation.

\section{Conclusion}

We presented here a favorable effect of intravitreal ketorolac in two patients with chronic post-cataract CME using an intensified scheme of four daily injections. Our findings are promising for the possible therapeutic role of intravitreal NSAIDs in complicated chronic CME cases persistent to conventional treatment. The development of long-acting NSAIDs formulations for intravitreal administration may have the potential to augment the therapeutic effect of these drugs for inflammatory macular edema.

\section{Acknowledgments}

This work was carried out in Heraklion, Crete, Greece. None of the authors had any financial interest with this study. There was no funding by any organization for this research.

\section{Disclosure}

The authors report no conflicts of interest in this work.

\section{References}

1. Irvine SR. A newly defined vitreous syndrome following cataract surgery. Am J Ophthalmol. 1953;36(5):599-619.

2. Yonekawa Y, Kim IK. Pseudophakic cystoid macular edema. Curr Opin Ophthalmol. 2012;23(1):26-32.

3. Sivaprasad S, Bunce C, Crosby-Nwaobi R. Non-steroidal anti-inflammatory agents for treating cystoid macular oedema following cataract surgery. Cochrane Database Syst Rev. 2012;2:CD004239.

4. Soheilian M, Karimi S, Ramezani A, Peyman GA. Pilot study of intravitreal injection of diclofenac for treatment of macular edema of various etiologies. Retina. 2010;30(3):509-515.

5. Margalit E, Boysen JL, Zastrocky JP, Katz A. Use of intraocular ketorolac tromethamine for the treatment of chronic cystoid macular edema. Can J Ophthalmol. 2010;45(4):409-410.

6. Wafapoor H MJ. Intravitreal ketorolac as a treatment of diabetic and non-diabetic macular edema. Invest Ophthalmol Vis Sci. 2006; 46(E-Abstract):4252.

7. Kim SJ, Doherty TJ, Cherney EF. Intravitreal ketorolac for chronic uveitis and macular edema: a pilot study. Arch Ophthalmol. 2012; 130(4):456-460.

8. Ramezani A, Fard Esmaeilpour N, Eskandari A, Rabbanikhah Z, Soheilian R, Soheilian M. Intravitreal diclofenac for refractory uveitic cystoid macular edema. J Ophthalmic Vis Res. 2013;8(1):47-52.

9. Maldonado RM, Vianna RN, Cardoso GP, de Magalhaes AV, Burnier MN Jr. Intravitreal injection of commercially available ketorolac tromethamine in eyes with diabetic macular edema refractory to laser photocoagulation. Curr Eye Res. 2011;36(8):768-773.

10. Reis Ado C, Vianna RN, Reis RS, Cardoso GP. [Intravitreal injection of ketorolac tromethamine in patients with diabetic macular edema refractory to retinal photocoagulation]. Arq Bras Oftalmol. 2010;73(4): 338-342. Portuguese.

11. Kim SJ, Adams NA, Toma HS, et al. Safety of intravitreal ketorolac and diclofenac: an electroretinographic and histopathologic study. Retina 2008;28(4):595-605.

12. Komarowska I, Heilweil G, Rosenfeld PJ, Perlman I, Loewenstein A. Retinal toxicity of commercially available intravitreal ketorolac in albino rabbits. Retina. 2009;29(1):98-105.

13. Margalit E, Kugler LJ, Brumm MV, et al. The safety of intraocular ketorolac in rabbits. Invest Ophthalmol Vis Sci. 2006;47(5): 2093-2099.

14. Tsilimbaris MK, Panagiotolglou TD, Tsika C, Pandeleondidis V, Kymionis G. Intravitreal injection of ketorolac tromethamine in postoperative cystoid macular edema. Invest Ophthalmol Vis Sci. 2008;49: 2693.

15. Shelsta HN, Jampol LM. Pharmacologic therapy of pseudophakic cystoid macular edema: 2010 update. Retina. 2011;31(1):4-12.

16. Kim SJ, Toma HS. Inhibition of choroidal neovascularization by intravitreal ketorolac. Arch Ophthalmol. 2010;128(5):596-600.

17. Elbendary AM, Shahin MM. Intravitreal diclofenac versus intravitreal triamcinolone acetonide in the treatment of diabetic macular edema. Retina. 2011;31(10):2058-2064.

18. Soheilian M, Eskandari A, Ramezani A, Rabbanikhah Z, Esmaeilpour NF, Soheilian R. Intravitreal diclofenac versus intravitreal triamcinolone for the treatment of uveitic cystoid macular edema. Retina. Epub 2013 Apr 11. 


\section{Publish your work in this journal}

Therapeutics and Clinical Risk Management is an international, peerreviewed journal of clinical therapeutics and risk management, focusing on concise rapid reporting of clinical studies in all therapeutic areas, outcomes, safety, and programs for the effective, safe, and sustained use of medicines. This journal is indexed on PubMed Central, CAS,

EMBase, Scopus and the Elsevier Bibliographic databases. The manuscript management system is completely online and includes a very quick and fair peer-review system, which is all easy to use. Visit $\mathrm{http}: / / \mathrm{www}$.dovepress.com/testimonials.php to read real quotes from published authors.

Submit your manuscript here: http://www.dovepress.com/therapeutics-and-clinical-risk-management-journal 